\title{
Field evaluation of oil formulations of Nomuraea rileyi (Farlow) Samson against Spodoptera litura and Helicoverpa armigera in groundnut
}

T. SHARMILA* AND K. MANJULA

Department of Entomology, S.V. Agricultural College (ANGRAU), TIRUPATI (A.P.) INDIA

\begin{tabular}{lll} 
ARITCLE INFO \\
\hline Received & $:$ & 19.11 .2014 \\
Revised & $:$ & 25.02 .2015 \\
Accepted & $:$ & 12.03 .2015 \\
\hline
\end{tabular}

KEY WORDS :

Oil formulations, Nomuraea rileyi, Spodoptera litura, Helicoverpa armigera

*Corresponding author:

Email: sharmila.telugu.47@gmail.com

\begin{abstract}
Nomuraea rileyi (Farlow) Samson is a potential entomopathogenic fungus against lepidopteran pests. In groundnut crop ecosystem, along with three oil formulations (sunflower, coconut and groundnut), two Wettable powder (corn flour and talc) and one crude formulation were evaluated against Spodoptera litura and Helicoverpa armigera during 2011-2012 at dry land farm, S.V. Agricultural College, Tirupati. The results indicated that groundnut oil based formulation of $N$. rileyi recorded significantly higher reduction of both S. litura $(82.46 \%)$ and H. armigera $(74.58 \%)$ larval population. The groundnut oil based formulation also recorded significantly lower per cent leaf damage by both S. litura (14.27\%) and H. armigera $(13.27 \%)$. However sunflower oil and coconut oil formulations also proved better than WP and crude formulations. Crude formulation was also found to be effective when compared to WP formulations in reducing the larval population, in recording lower per cent leaves damaged at 15 days after treatment against both pests.
\end{abstract}

How to view point the article : Sharmila, T. and Manjula, K. (2015). Field evaluation of oil formulations of Nomuraea rileyi (Farlow) Samson against Spodoptera litura and Helicoverpa armigera in groundnut. Internat. J. Plant Protec., 8(1) : 142-147. 